\title{
Guía de Práctica Clínica Manejo de las exacerbaciones agudas de la Enfermedad Pulmonar Obstructiva Crónica
}

Agency for healthcare research and quality by the Duke University evidence-based practice center. Evidence report/ technology assessment number 19.

La enfermedad pulmonar obstructiva crónica (EPOC) es la cuarta causa de muerte en países occidentales. En EE.UU. genera 13.760 .000 consultas y 297.000 hospitalizaciones anuales, a un costo de 18 mil millones de dólares.

Su historia natural está caracterizada por exacerbaciones agudas con aumento de la disnea basal, aumento de la cantidad de expectoración o producción de esputo purulento.

Estas exacerbaciones aumentan la mortalidad a corto plazo por sí mismas o por enfermedades comórbidas, especialmente cardiovasculares, además de disminuir el status funcional del paciente y su calidad de vida.

El objetivo de este reporte fue evaluar la evidencia publicada disponible sobre el diagnóstico, pronóstico y manejo de la EPOC reagudizada y el uso de ventilación no invasiva con presión positiva en pacientes con falla respiratoria aguda por esta causa Para ello se revisaron los trabajos publicados en el período 1966 1999 mediante MEDLINE, EMBASE Y Cochrane Controlled Trials Register.

Las preguntas a responder mediante esta revisión se centraron en tres ítems principales:

\section{I) Evaluación clínica}

¿Qué tan útil es la evaluación clínica (incluyendo historia, examen físico laboratorio y $\mathrm{Rx}$ ) para discriminar entre EPOC y otras causas de insuficiencia respiratoria?

¿Qué tan útil es ésta para predecir el prónostico o el nivel de cuidados requeridos? (hospitalización en piso o UTI, necesidad de ventilación, recaída post-alta en guardia)

\section{2) Tratamiento}

¿Qué tan efectivas son las modalidades clínicas utilizadas en e tratamiento de la EPOC (antibióticos, broncodilatadores, corticoides, mucolíticos) para aliviar los síntomas, resolver la causa de la exacerbación, prevenir la internación y disminuir la estadía de ésta?

\section{3) Ventilación con presión positiva no invasiva}

¿Puede ésta prevenir la intubación o mejorar el pronóstico, incluyendo mortalidad, morbilidad, duración de la hospitalización y costos?

Las conclusiones en las cuales hay evidencia demostrada son las siguientes:

\section{1) Evaluación clínica}

Las $\mathbf{R x}$ de los pacientes con EPOC reagudizada tienen una relativamente alta frecuencia de anormalidades, como infiltrados o edema pulmonar, especialmente si se las compara con las $\mathrm{Rx}$ de los pacientes con asma.

Hay pocos datos disponibles que ayuden a cuantificar el riesgo de Tromboembolismo Pulmonar en pacientes con EPOC reagudizada, con o sin Trombosis Venosa Profunda conocida.

La medición del FEV1 durante la reagudización no correlaciona bien con la $\mathrm{PaO} 2$, pero sí se correlaciona con la $\mathrm{PCO} 2$ y el $\mathrm{pH}$ La medición del FEV1 durante la reagudización es generalmente insegura, además el uso del pico-flujo no correlaciona bien con el FEV1 para sustituirlo.

Los datos de la historia clínica individual del paciente (consultas en la semana previa, número de exacerbaciones en el último año) fueron consistentemente identificados como predictores de recaídas, también fueron predictores de recaídas y/o internación la función pulmonar basal, medida como FEV1 o CVF y la medición del FEV1 o el nivel de gases arteriales durante la exacerbación. La mortalidad se relacionó con la historia del curso clínico del paciente (espirometría basal, número y frecuencia de reagudizaciones previas, respuestas a los tratamientos previos) y las mediciones de gases durante el estado agudo o FEV1, que también fueron predictores de necesidad de ventilación.

\section{2) Tratamiento}

Los pacientes con mayor evidencia de infección bacteriana (es puto purulento) y enfermedad más severa, se beneficiarían más con el uso de antibióticos, aunque esto no fue demostrado en forma concluyente.

Los beta2 agonistas e ipratropio inhalatorios mostraron similares efectos en ensayos comparativos, pero no hay ningún tra bajo controlado con placebo o no-tratamiento que haya demostrado en forma concluyente el beneficio clínico del uso de ambos (sólo está demostrado un beneficio mínimo, lo que no deja de ser sorprendente)

El ipratropio está asociado con menores efectos adversos que los beta2 agonistas, aunque debe ser utilizado con precaución en pacientes con retención urinaria preexistente.

Los broncodilatadores tienen similar efecto en el EPOC estable utilizados tanto en forma de aerosol o nebulizable, aunque en e paciente descompensado es preferible la nebulización.

No se demostró ningún beneficio de la aminofilina parenteral en trabajo placebo-controlados con respecto a mejoría clínica o dis minución de internaciones o frecuencia de recaídas. Presenta, además, numerosos y severos efectos indeseables.

Hay una fuerte evidencia que un curso sistémico de corticoides es beneficioso en pacientes hospitalizados por EPOC reagudizada. Estos reducen el riesgo de falla del tratamiento en un $10 \%$, y producen una mejoría del FEV1 de 0,1 litros en las primeras horas o días del tratamiento.

La dosis óptima y la duración del tratamiento no fue bien establecida en los trabajos disponibles, se destaca un trabajo en que una do sis de $30 \mathrm{mg} /$ día durante 3 días fue efectiva y otro que no demostró diferencias significativas entre 2 y 8 semanas de tratamiento. Cabe destacar que no se han encontrado trabajos donde hayan sido testeados adecuadamente los corticoides inhalatorios en pacientes con EPOC reagudizada.

El efecto adverso más frecuente con el uso de corticoides fue la hiperglucemia.

Ningún medicamento mucolítico (entre ellos, ambroxol, bromexina y S-carboximetil cisteína) demostró mejorar la función ventilatoria durante la reagudización de la EPOC, al igual que la kinesioterapia respiratoria.

\section{3) Ventilación con presión positiva no invasiva}

Se demostró que es una alternativa efectiva en relación a la ventilación mecánica con intubación endotraqueal

\section{Conclusión}

La mayoría de los estudios tratan sobre pacientes EPOC hospitalizados, pese a que la enfermedad se maneja especialmente en un contexto ambulatorio.

En los trabajos analizados la descripción de los sujetos no es su ficiente como para caracterizar la gravedad de la enfermedad de la población estudiada, por lo que es necesario desarrollar, validar y usar un mejor sistema para describir la severidad de los pacientes EPOC reagudizados para poder, entre otras cosas, unificar el manejo y efectuar trabajos comparativos. 